\title{
Spatial Spillover Effect and Sources of City-Level Haze Pollution in China: A Case Study of Guangdong Provinces
}

\author{
Shiming Liao, Dong Wang, Zhijun Liang, Changyou Xia, Hao Guo*, Wenjia Zhao \\ School of Economics and Management, Harbin Institute of Technology, Shenzhen, Guangdong, China
}

Received: 10 July 2019

Accepted: 27 October 2019

\begin{abstract}
With severe haze pollution continuing to frequently occur in many regions of China in recent years, increasing research effort has been made to study the source and control of haze pollution using socio-economic factors. Based on the urban panel data of 21 cities in Guangdong Province, South China, from 2005 to 2016, this paper analyzes the spatial and temporal evolution trend, spatial autocorrelation and influencing factors of Guangdong's haze pollution through spatial econometric methods with inverse distance weight. First, the results show that the haze pollution of 21 cities in Guangdong Province has strong spatial autocorrelation and spatial clustering phenomenon. Aggregation areas of heavy air pollution are located in the Pearl River Delta region centered on Guangzhou, Foshan, Zhongshan and Dongguan. Those cities should be targeted as priority haze-pollution-reduction areas. Secondly, significant spatial dependence and spatial spillover effects of haze pollution in Guangdong are demonstrated by the spatial econometric models. Joint prevention and control of haze pollution between cities are therefore important and necessary. Thirdly, the direct and indirect effects of energy consumption on haze pollution are positive and significant at the $1 \%$ level. Meanwhile, population, foreign direct investments (FDI) and the ratio of the secondary industry (e.g., manufacturing and construction industries) relative to the service industry also play important roles in haze pollution, and all of them have positive effects on air pollution. However, the environmental Kuznets curve (EKC) hypothesis is not supported by the economy-emission data of Guangdong. Economic growth and car density are not significant factors in deciding the level of haze pollution. To effectively improve the local air quality, the government is recommending the introduction of policies for adjusting the structures of energy, economy and FDI, promoting the research, development and application of clean technologies, and enhancing the awareness of energy conservation among residents and enterprises.
\end{abstract}

Keywords: haze pollution, $\mathrm{PM}_{2.5}$, energy consumption, FDI, spatial autocorrelation, spatial econometric models

*e-mail: guohao_89@126.com 


\section{Introduction}

Haze pollution is mainly composed of $\mathrm{PM}_{2.5}$ (particulate matter with an aerodynamic diameter less than 2.5 micrometers) and $\mathrm{PM}_{10}$ [1]. It generally originates from two sources: the first is directly produced by energy combustion, industrial process and dust; the second is produced by its precursors, such as $\mathrm{SO}_{2}, \mathrm{NOx}, \mathrm{CO}$, and VOCs through physicochemical reaction processes. Hazy weather seriously endangers the health of people and causes immeasurable economic losses. According to the World Health Organization (WHO), the annual economic loss caused by premature human death due to air pollution accounts for about $1.2 \%$ to $2 \%$ of global GDP [2]. However, the data show that China's air pollution situation may be even worse than the global average [3]. At the end of 2016, a recordbreaking "cross-year haze pollution" of 200 hours occurred in the Beijing-Tianjin-Hebei region, as well as in neighboring Shandong and Henan Provinces [4]. Clearly, the problem of air pollution has now become a major obstacle for the sustainable development of China's economy. The economically prosperous Pearl River Delta region in Guangdong Province has also been suffering from serious air pollution in recent years. Given the policy importance of the haze pollution issue, it is imperative to understand why some regions in Guangdong have more severe $\mathrm{PM}_{2.5}$ concentrations than others.

In current literature, there are four major approaches to study the origins of haze pollution. The first one mainly analyzes the physical and chemical processes of the source and formation of haze pollution [5-7]. This type of research focuses on the contributions of emissions and weather conditions to regional haze and the secondary pollution caused by weather conditions, but often ignores the effects of economic and social factors. The second one adopts the input-output model and uses the structural decomposition analysis to examine the driving factors behind the smog pollutions in China [8]. However, this type of research is relatively lagging and discontinuous, and only focuses on a few socioeconomic factors due to the limitation of inputoutput tables. The third one constructs a computable general equilibrium (CGE) model to analyze the effects of energy structure and technology on haze pollution and simulate the outcomes of different policy combination [9]. Similarly, it is also based on input-output tables and must be supported with highquality data. The inaccuracy of its parameters and the strong assumptions of the model often make the conclusion questionable. The fourth one employs a typical econometric method. Since this method is capable of studying the influence of various economic and social factors on haze pollution, it is widely used in numerous studies - especially those dealing with panel data. According to empirical studies, the main human factors affecting the degree of smog pollution include economic growth rate [10], urban scale [11], the proportion of industry [12], high coal consumption ratio in the energy structure [13], urbanization rate and the number of motor vehicles [14]. Most of these studies using traditional time series or panel models ignore the spatial correlation. However, haze pollution is not a local problem [15]. Under the influence of atmospheric transfer and the connection of economic activity between different cities, smog pollution has a strong spatial correlation $[16,17]$. It is necessary to take spatial characteristics into consideration. In the view of spatial effects, the relationship between air pollution and foreign direct investment [18], environmental regulation [19], industrial transfer [20], energy consumption [21], $\mathrm{CO}_{2}$ emissions reduction activities [22] and economic growth $[17,23]$ have also recently been verified by the province data of China. For example, Liu and Feng (2019) show that industrial transfer will intensify haze pollution in the transferred-in areas [20]. Tang et al. (2018) have revealed that energy consumption also has a significant and positive effect on $\mathrm{PM}_{10}$ pollution in China during 2004-2014 [21]. Liu and Lin (2019) find that an inverted $\mathrm{N}$ relationship exists between environmental pollution and economic development [24].

To sum up, on the one hand previous literature has analyzed the spatial distribution conditions, regional characteristics, and their influencing factors of haze pollution at the provincial level of China. However, there is little literature at the city level. Since there are more than 20 provinces with an area of more than 150,000 square kilometers in China, studying haze pollution at the provincial level is overgeneralized and lacks the data accuracy to reflect the actual cause of haze pollution in specific cities, which are the major administrative units in controlling air pollution in China. Therefore, studying the spillover effect of air pollution at the city level is more helpful for providing customized cleanair policy advice for local governments. On the other hand, many studies have investigated the sources, compositions, formation process, and influences of haze pollution in China, but a systematic analysis for socioeconomic influence factors of haze pollution has not been reported clearly. Moreover, those studies use data of province level and construct a spatial weight matrix with the simplest 0-1 adjacency matrix. In Guangdong Province, this is inappropriate because, for example, Guangzhou and Shenzhen have a strong connection on the economy, population, transportation and industry and are very close to each other, but they have no common boundary or vertex in the map.

As a result, this paper has four main advantages over the existing literature. Firstly, this study proposes a comprehensive and systematic mechanism model to understand the influence of energy, economic and social factors on haze pollution (see Fig. 1). This means that when discussing the socio-economic factors affecting smog pollution, it is necessary to take into account the spatial spillover effect of smog pollution in order to obtain a better understanding of the source and formation process of haze pollution. This new 


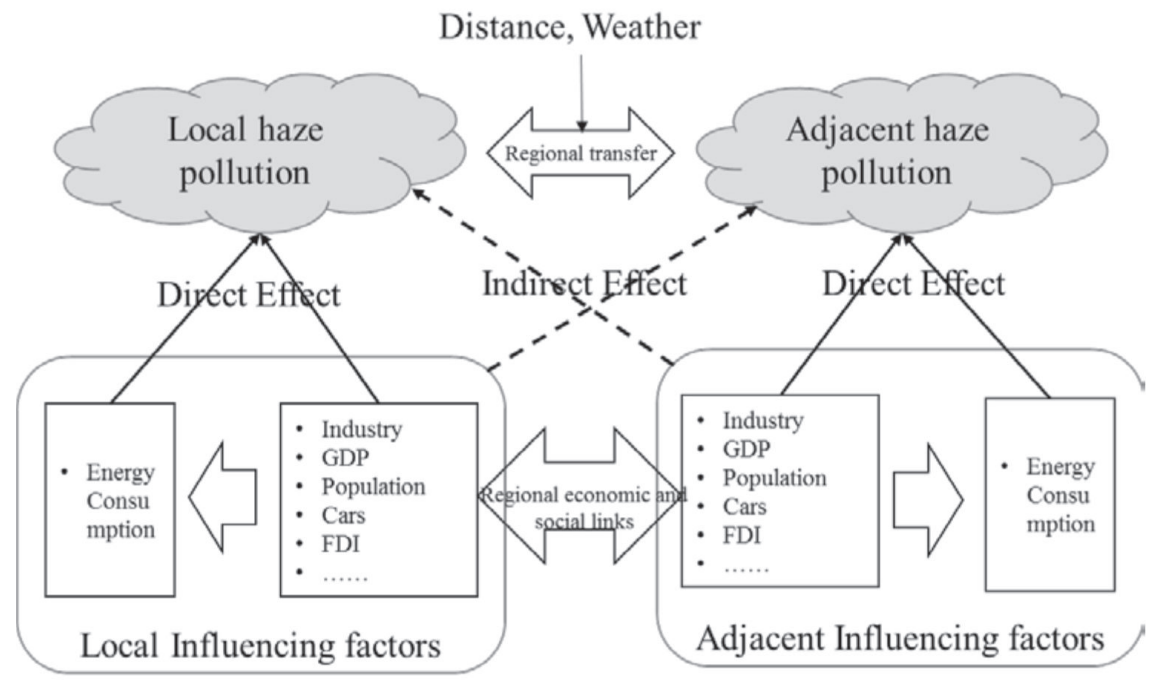

Fig. 1. Mechanism model demonstrating the influence of energy, economic and social factors on haze pollution.

knowledge is important for the government to make corresponding treatment measures to effectively reduce the level of air pollution. Secondly, this paper is the first study that uses panel data of 21 cities' annual averaged $\mathrm{PM}_{2.5}$ concentrations to explore the relationship between energy consumption and haze pollution in Guangdong. The utilization of urban data has made it more accurate to capture spatial spillover effect than most previous studies using provincial data. Thirdly, we extend the STIRPAT model and employ spatial econometric models with inverse distance weight to investigate the effect of energy consumption on haze pollution in Guangdong. It takes the spatial term into consideration and studies the spillover effects of factors on haze pollution, which is different from ordinary panel models. Finally, in order to reduce the bias and risk of results caused by missing variables, we include a series of variables such as economic development, population, FDI, civil vehicle density and industrial structure into the spatial model.

The purpose of this article is to:

1. Propose an integrated space framework of the influencing process of energy and economic and social factors on haze pollution.

2. Construct inverse distance weight and use exploratory spatial data analysis (ESDA) to estimate the spatial autocorrelation of smog pollution in Guangdong at the city level.

3. Using spatial econometric models such as the spatial lag model (SLM) and the spatial error model (SEM) to study the influencing factors of smog pollution in Guangdong and decompose the coefficient estimation of explanatory variables into direct effects and indirect effects by using the method of partial differentiation.

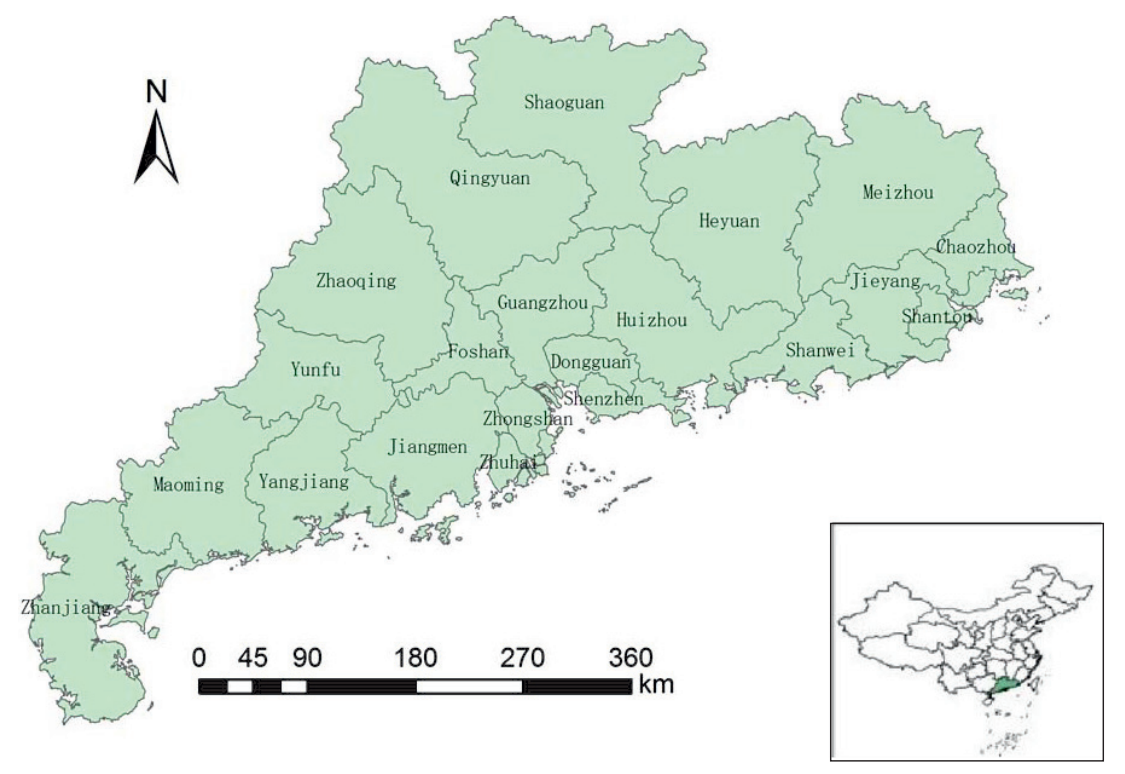

Fig. 2. Geographical location of Guangdong province and 21 cities. 


\section{Materials and Methods}

\section{Study Area}

Guangdong province is located on the southern coast of mainland China, covering an area of approximately $179,800 \mathrm{~km}^{2}$ and having the largest population in China (Fig. 2). It borders with Fujian, Jiangxi and Hunan Provinces and Guangxi Zhuang Autonomous Region from east to west; it is adjacent to Hong Kong and Macao. Since 1989, Guangdong has topped the total GDP rankings among all the provinces of China. By 2017, Guangdong had a resident population of 112.69 million. There were eight cities with a population density of more than 1,000 people per square kilometer in Guangdong in 2017, and six of the cities are in the Pearl River Delta region (Fig. 2). With the process of rapid urbanization and industrialization, the Pearl River Delta region has encountered severe air pollution issues of high-frequency acid rain, high-concentration ozone and particulate matters and continual smog weather.

\section{Data Sources and Descriptive Statistics for Variables}

This study employs balanced panel data from 21 cities in Guangdong from 2005 to 2016 as a sample, and obtains the data of GDP per capita, FDI, industrial structure, car numbers, population and city area from the Guangdong Statistical Yearbook, which is accessible on the website of the Statistics Bureau of Guangdong Province [25]. The annual average $\mathrm{PM}_{2.5}$ of each city during 2005-2016 in Guangdong is derived from the data set published by the Social Economic Data and Application Center (SEDAC) at Columbia University [26]. These data are consistent with local $\mathrm{PM}_{2.5}$ monitoring data of Guangdong. The definitions and summaries of the variables involved are shown in Table 1.

\section{Spatial Association with Exploratory Spatial Data Analysis (ESDA)}

ESDA, a method of describing spatial autocorrelation, is employed to detect the spatial properties of a phenomenon [27]. It contains global spatial correlation and local spatial correlation. The global spatial association is generally tested using the global Moran index. Moran (1950) proposed Moran's I test for the association of spatial econometric models [28]. It is defined as follows:

$$
\text { Moran's I }=\frac{\sum_{i=1}^{n} \sum_{j=1}^{n} w_{i j}\left(y_{i}-\bar{y}\right)\left(y_{j}-\bar{y}\right)}{S^{2} \sum_{i=1}^{n} \sum_{j=1}^{n} w_{i j}}
$$

...where $S^{2}=\frac{1}{n} \sum_{i=1}^{n}\left(y_{i}-\bar{y}\right)^{2}, \bar{y}=\frac{1}{n} \sum_{i=1}^{n} y_{i}, y_{i}$ is the $\mathrm{PM}_{2.5}$ value of the region $\mathrm{i}, \mathrm{n}$ is the total number of regions, and $w_{i j}$ represents the spatial weight matrix.

The local indicator of spatial association (LISA) is used to measure the degree of spatial aggregation of haze pollution among cities. The formula for calculating the local Moran's I index is as follows:

$$
I_{i}=\frac{\left(y_{i}-\bar{y}\right) \sum_{j=1}^{n} w_{i j}\left(y_{j}-\bar{y}\right)}{S^{2}}
$$

In formula (2), $I_{i}$ is the local Moran's I index of the city $i$, and the other variables have the same meaning as the global Moran's I index formula. If $I_{i}>0$, a high-value city is surrounded by a high-value area ("high-high") or a low-value city is surrounded by a low-value area ("low-low"); if $I_{i}>0$, it means that a high-value city is surrounded by a low-value area ("high-low"), or a low-value city is surrounded by a high-value area ("low-high"). A Moran scatter plot can be drawn by Stata 14.1 software. The scatter plot has four quadrants, corresponding to the four cases above.

The main difference between the spatial panel model and the traditional model is that a spatial equation with weight is constructed. In this study, the spatial weight matrix is based on the inverse of distance, generated by ArcMap 10.2. The distance is calculated with the Euclidean distance method, and the neighborhood search threshold is 1.2317 degrees. At the same time, it is standardized. The spatial weight matrix expresses the spatial distribution of observation variables in different regions. It is defined as follows:

Table 1. Descriptive statistics for variables.

\begin{tabular}{|c|c|c|c|c|c|c|c|}
\hline Variable & Unit & definition & Obs & Mean & Std. Dev. & Min & Max \\
\hline PM $_{25}$ & ug/m $\mathrm{m}^{3}$ & PM $_{2.5}$ & 252 & 30.826 & 6.578 & 18.413 & 48.811 \\
\hline ECP & tce/10000 persons & Energy consumption per capita & 252 & 2.663 & 1.377 & 0.419 & 5.687 \\
\hline GDPP & 10000 yuan per capita & GDP per capita & 252 & 3.825 & 2.921 & 0.742 & 13.710 \\
\hline POPU & million & Population & 252 & 4.883 & 2.676 & 1.416 & 14.044 \\
\hline INDUS & 1 & Secondary Industry / Service industry & 252 & 1.116 & 0.328 & 0.385 & 2.094 \\
\hline FDI & $\%$ & FDI / GDP & 252 & 2.768 & 2.312 & 0.102 & 10.870 \\
\hline CARDEN & Civil car per km ${ }^{2}$ & Civil car number / area & 252 & 129.210 & 251.409 & 2.136 & 1591.589 \\
\hline
\end{tabular}




$$
w_{i j}=\left\{\begin{array}{c}
\frac{1}{d_{i j}}, i \neq j \\
0, i=j
\end{array}\right.
$$

\section{Extended STIRPAT Model and Spatial Econometric Model}

According to IPAT identity put forward by Ehrlich and Holdren (1971) [29], population increase plays an important role in the increase of environmental pressure. Based on the IPAT identity, Dietz and Rosa (1994) [30] constructed a random model, named the STIRPAT model, which has the following form:

$$
I_{i t}=a P_{i t}^{b} A_{i t}^{c} T_{i t}^{d} \varepsilon_{i t}
$$

...where I is environmental pressure (Impact), $\mathrm{P}$ represents population number (Population), A means affluence degree (Affluence), T denotes the technology, $\mathrm{i}$ and $\mathrm{t}$ are the city and year respectively. "a" is the constant item. "b, c, and d" represent the exponents of population, affluence, and technology, and $\varepsilon$ is the error term. Haze pollution $\left(\mathrm{PM}_{25}\right)$ is used to express the environmental pressure in different cities. Following Wen et al. (2015) [31] and others, this paper extends and modifies the STIRPAT model by using six influencing factors, including per capita energy consumption (ECP), per capita GDP (GDPP), industrial structure (INDUS), the ratio of FDI to GDP (FDI), population number (POPU) and car density (CARDEN).

$$
\begin{gathered}
P M 25_{i t}=a \cdot P O P U_{i t}^{b} \cdot G D P P_{i t}^{c} \cdot E C P_{i t}^{d} \\
\cdot I N D U S_{i t}^{e} \cdot F D I_{i t}^{f} \cdot C A R D E N_{i t}^{g} \cdot \varepsilon_{i t}
\end{gathered}
$$

The Kuznets curve was first proposed by the economist Simon Kuznets in 1955 when studying the relationship between per capita income and income distribution fairness (Kuznets, 1955) [32]. Later, during the early 1990s, Grossman and Krueger innovatively applied the Kuznets curve to the field of environmental quality, and suggested that the relationship between per capita income and environmental quality demonstrates a form of an inverted U-shaped curve and a turning point at a per capita income of $\$ 8000$ [33]. Some scholars also test the EKC of environmental pollutants and economic growth with the provincial data of China $[34,35]$ and America [36]. When the logarithmization treatment is made on both sides of 208 Equation (5) and the EKC hypothesis is contained, the model can be expanded and modified as follows:

$$
\begin{gathered}
\ln P M 25_{i t}=\beta_{0}+\beta_{1} \ln P O P U_{i t}+\beta_{2} \ln G D P P_{i t}+ \\
\beta_{3} \ln G D P P_{i t}^{2}+\beta_{4} \ln E C P_{i t}+\beta_{5} \ln I N D U S_{i t}+ \\
\beta_{6} \ln F D I_{i t}+\beta_{7} \ln C A R D E N_{i t}+\ln \varepsilon_{i t}
\end{gathered}
$$

In Equation (5), spatial autocorrelation of haze pollution among cities are ignored, which may cause invalid outcomes of ordinary panel models. Based on the extended STIRPAT model and the different impact modes of spatial terms, this paper constructs two spatial econometric models, namely the spatial lag model (SLM) and spatial error model (SEM). The SLM mainly discusses whether there is a spatial autocorrelation of haze pollution or spillover effect in each city as follows:

$$
\begin{aligned}
& \ln P M 25_{i t}=\rho \sum_{j=1}^{n} w_{i j} \ln P M 25_{j t}+\beta_{0}+ \\
& \beta_{1} \ln P O P U_{i t}+\beta_{2} \ln G D P P_{i t}+\beta_{3} \ln G D P P_{i t}^{2}+ \\
& \beta_{4} \ln E C P_{i t}+\beta_{5} \operatorname{lnINDUS} S_{i t}+\beta_{6} \ln F D I_{i t}+ \\
& \beta_{7} \operatorname{lnCARDEN_{it}}+\mu_{i}+\varepsilon_{i t}
\end{aligned}
$$

$\ldots$ where $\sum_{j=1}^{n} w_{i j} \ln P M 25_{j t}$ denotes spatial lag variable, $\rho$ means the spatial autoregressive coefficient, $w_{i j}$ is the spatial weight matrix of size $21 \times 21, \mu_{i}$ represents the individual effect of city $\mathrm{i}$, and $\varepsilon_{i t}$ is the error term.

In the SEM, the spatial dependent effect mainly exists in the error term, which is used to reflect the differences of the interaction among variables in different cities with different geographical locations through the following formula.

$$
\begin{gathered}
\ln P M 25_{i t}=\beta_{0}+\beta_{1} \ln P O P U_{i t}+\beta_{2} \ln G D P P_{i t}+ \\
\beta_{3} \ln G D P P_{i t}^{2}+\beta_{4} \ln E C P_{i t}+\beta_{5} \ln I N D U S_{i t}+ \\
\beta_{6} \ln F D I_{i t}+\beta_{7} \ln C A R D E N_{i t}+\gamma_{t}+ \\
\lambda \sum_{j=1}^{n} w_{i j} \varepsilon_{t}+v_{i t}
\end{gathered}
$$

...where $\gamma_{t}$ is time effect, $w_{i j}$ represents the spatial weight of error term, $\lambda$ is the spatial error coefficient and $v_{i j}$ is the random error vector of a normal distribution.

\section{Results and Discussion}

\section{Global Spatial Correlation of Haze Pollution}

Table 2 shows that the global Moran's index for 21 cities in Guangdong is positive, fluctuating in the range of $0.685-0.816$. It shows an increasing trend from 2005 to 2008. Although it decreases to 0.752 in 2009 , it starts to increase again from 2009 to 2011, with a slow decrease from 2012 to 2016. The value of $\mathrm{Z}$ is larger than 2.58 and the value of $p$ is less than 0.01 . This means that there is a significant spatial positive autocorrelation of haze pollution in 21 cities from 2005 to 2016. In other words, haze pollution in Guangdong is not distributed randomly and there may be agglomeration in highly polluted areas.

Figs 3a), 3b) and 3c) present Moran scatter plots of haze pollution of 21 cities in Guangdong in 2005, 2010, 
Table 2. Global Moran's I of haze pollution in 21 cities of Guangdong province.

\begin{tabular}{|l|c|c|c|c|c|}
\hline Years & Moran's & $\mathrm{E}(\mathrm{I})$ & Variance & Z value & P value \\
\hline 2005 & 0.685 & -0.050 & 0.023 & 4.842 & 0.000 \\
\hline 2006 & 0.712 & -0.050 & 0.023 & 4.988 & 0.000 \\
\hline 2007 & 0.780 & -0.050 & 0.024 & 5.392 & 0.000 \\
\hline 2008 & 0.800 & -0.050 & 0.024 & 5.542 & 0.000 \\
\hline 2009 & 0.752 & -0.050 & 0.023 & 5.234 & 0.000 \\
\hline 2010 & 0.776 & -0.050 & 0.024 & 5.383 & 0.000 \\
\hline 2011 & 0.816 & -0.050 & 0.024 & 5.647 & 0.000 \\
\hline 2012 & 0.798 & -0.050 & 0.023 & 5.550 & 0.000 \\
\hline 2013 & 0.784 & -0.050 & 0.023 & 5.454 & 0.000 \\
\hline 2014 & 0.731 & -0.050 & 0.023 & 5.118 & 0.000 \\
\hline 2015 & 0.705 & -0.050 & 0.023 & 4.972 & 0.000 \\
\hline 2016 & 0.693 & -0.050 & 0.023 & 4.883 & 0.000 \\
\hline
\end{tabular}

and 2015, respectively, indicating that most regions are located in the first quadrant ("high-high" type) and the third quadrant ("low-low" type). So the number of regions located in the first and third quadrants account for $80.95 \%, 85.71 \%$, and $76.19 \%$ of the total number of regions, respectively, in 2005, 2010 and 2015. This also suggests that most cities of Guangdong show similar spatial aggregation characteristics with their neighboring cities. In other words, heavy haze-polluted regions tend to be adjacent to heavy haze-polluted regions and vice versa.

In order to show the regions with strong autocorrelation in local space clearly, the LISA significance map is shown in Fig. 4. In 2005 (see Fig. 4a), 4 cities (Guangzhou, Foshan, Dongguan and Zhongshan) showed "high-high" aggregation characteristics. In 2010 (see Fig. 4b), 5 cities exhibited the "high-high" feature, including Zhaoqing and the previous four cities. In 2015 (see Fig. 4c), there were still four "high-high" cities, which were the same as in 2005. In comparison, Meizhou, Chaozhou, Jieyang, Shantou and Shanwei were "low-low" cities. They are the cities with low haze pollution together with its surrounding cities, which were less economically developed cities in the east area of Guangdong. The haze pollution is concentrated in the Pearl River Delta region, which has a developed economy, dense population, high industrialization and urbanization, especially in Guangzhou, Foshan, Dongguan and Zhongshan. Over 12 years, the high-high type and low-low type are almost unchanged. Therefore, we conclude that the spatial cluster effects of haze pollution in Guangdong are obvious and persistent.

\section{Spatial Autocorrelation Test and Model Selection}

In order to choose a better model to test the relationship between energy consumption and haze pollution, we make a comparison between SLM and SEM. Anselin (1996) [37] came up with a spatial regression model decision rule by analyzing the values a)

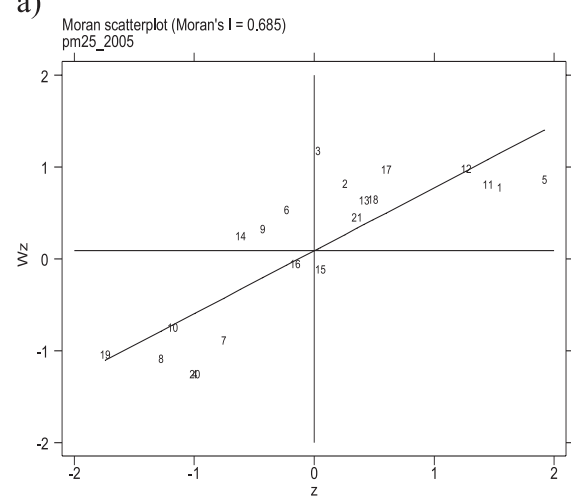

b)

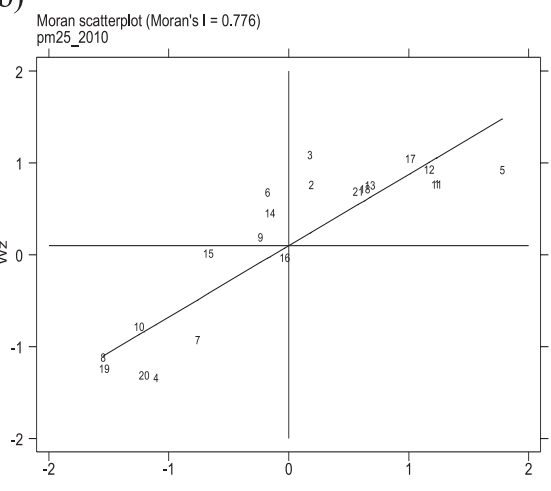

c)

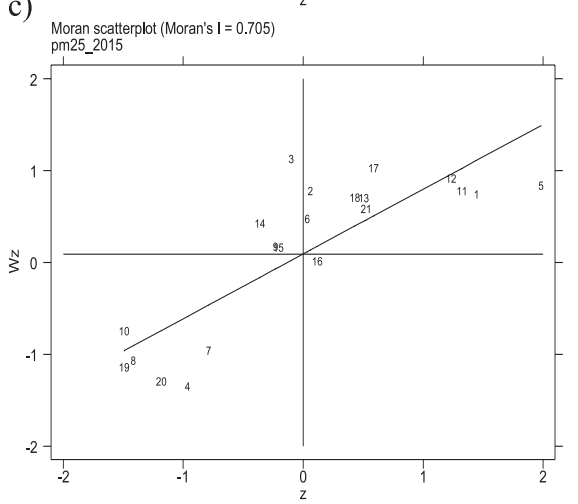

Fig. 3. The Moran scatter plot of haze pollution in Guangdong province. 


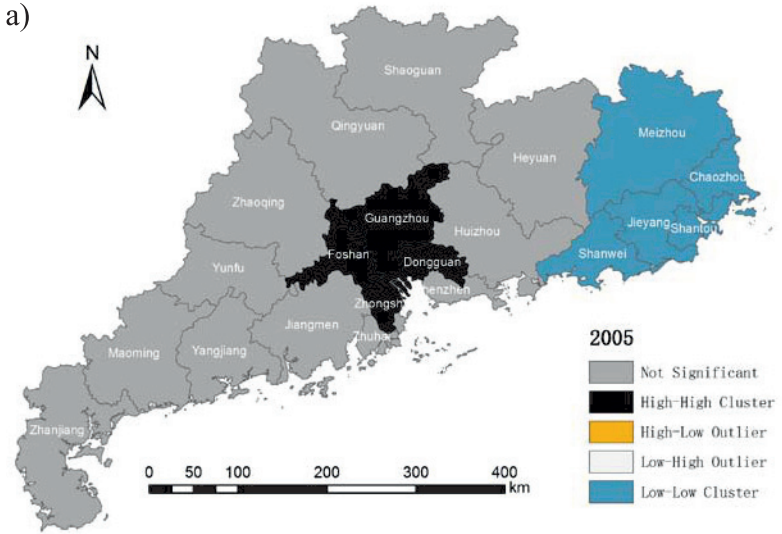

b)

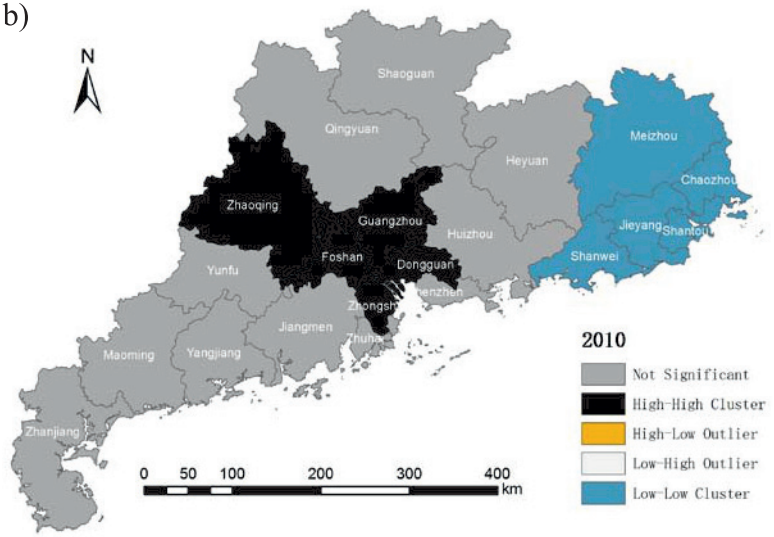

c)

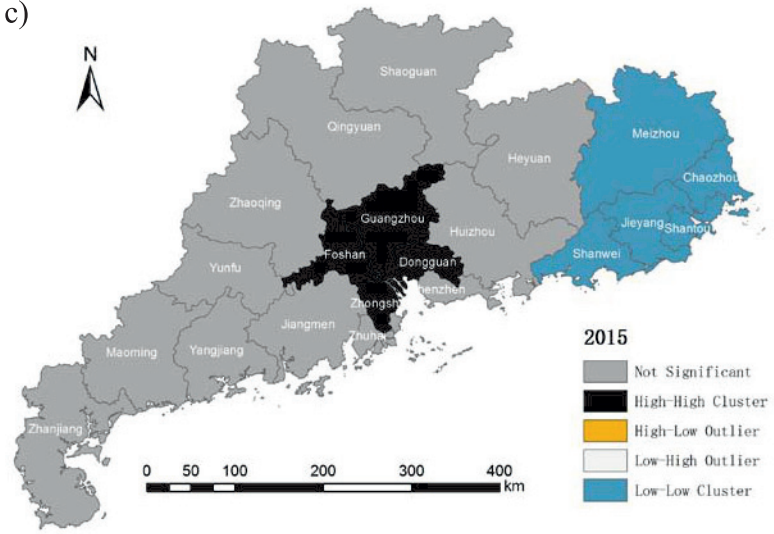

Fig. 4. LISA cluster maps of haze pollution in Guangdong province.

of Lagrange multiplier (lag) and Lagrange multiplier (error). LM-lag and LM-error are used to test the SLM and the SEM respectively. If only one of them is significant, then we can choose the corresponding model directly. If both are significant, the values of Robust LM-lag and Robust LM-error need to be observed. If the Robust LM-lag value is more significant than the
Robust LM-error value, the suitable model is SLM. Conversely, if the Robust LM-error value is more significant than the Robust LM-lag value, the SEM model is selected. The testing results of the spatial correlation are shown in Table 3.

Table 3 shows that both results of LM-lag and LM-error are significant at the 0.01 significance level. We further compare Robust LM values to judge which of the models is more appropriate. The Robust Lagrange multiplier (lag) value is significant at the 0.01 significance level. However, the Robust Lagrange multiplier (error) value is not significant at the 0.05 significance level. As for Robust LM-lag and Robust LM-error, the former is more significant than the latter. It suggests that the model under the condition of SLM is the optimal model. Hence, we choose SLM over SEM to analyze the effect of energy consumption on haze pollution in Guangdong.

\section{Comparative Analysis of the Results of Three-Panel Models}

Based on the Lagrange multiplier values of OLS, we can select a more suitable model from the SLM and SEM. The least square method is always used to estimate general panel data. However, it may lead to partial or invalid regression results because of not considering the spatial autocorrelation. In this study, the panel data of 21 cities in Guangdong from 2005 to 2016 are selected for empirical analysis. The data are analyzed by using the traditional panel model with random-effects method first, according to the estimation results of the Hausman test, in model 1 in Table 4. Then we use Stata 14.1 software to analyze the space-fixed effect, time-fixed effect, and time-space-fixed effect of SLM and SEM, respectively. However, from the results of these models, the robustness of fit of timefixed effect is the highest, which is the most suitable model, so we only list the results of the time fixed effect model in this paper, which is the Model 2 and Model 3 in Table 4. Therefore, SLM and SEM models with time fixed-effects are used to estimate the parameters of factors. By comparing the spatial estimation results of SLM and SEM in Table 4, the log likelihood (Log-L) and $\mathrm{R}^{2}$ values in SLM are more significant than SEM, and based on the Hausman test, the time-fixed effect of SLM is an optimal choice which is applied to explain the effect of energy consumption on haze pollution in Guangdong.

Model 1 does not contain the spatial characteristic, and only per capita energy consumption, FDI and population have a positive impact on haze pollution

Table 3. Spatial autocorrelation test of haze pollution in Guangdong.

\begin{tabular}{|c|c|c|c|}
\hline LM-Lag & LM-Error & Robust LM-Lag & Robust LM-Error \\
\hline $169.481 * * *(0.000)$ & $162.101 * * *(0.000)$ & $10.298 * * *(0.001)$ & $2.918^{*}(0.088)$ \\
\hline
\end{tabular}

Note: $\mathrm{P}$ values in the parentheses, ***,**and $*$ denote a significance of $1 \%, 5 \%$ and $10 \%$. 
Table 4. The Results of the three panel models.

\begin{tabular}{|c|c|c|c|}
\hline Variables & Ordinary Panel Model & SEM & SLM \\
\hline $\ln \mathrm{ECP}$ & $0.216^{* * *}(2.66)$ & $0.077 * * *(-3.83)$ & $0.075 * * *(-3.87)$ \\
\hline $\ln \mathrm{GDPP}$ & $-0.134(-1.56)$ & $-0.096 * *(-2.11)$ & $0.004(-0.1)$ \\
\hline $\ln \mathrm{GDPP} 2$ & $-0.021 \quad(-1.39)$ & $-0.007(-0.56)$ & $-0.011(-1.04)$ \\
\hline $\ln \mathrm{INDUS}$ & $0.052(1.34)$ & $0.040 * * *(-2.71)$ & $0.053 * * *(-2.77)$ \\
\hline $\ln \mathrm{FDI}$ & $0.072 * * *(5.51)$ & $0.013(-1.35)$ & $0.015 * *(-2.19)$ \\
\hline $\ln \mathrm{POPU}$ & $0.143 * *(2.12)$ & $0.075 * * *(-7.19)$ & $0.090 * * *(-7.19)$ \\
\hline $\ln \mathrm{CARDEN}$ & $-0.026(-0.80)$ & $0.034 * * *(-3.88)$ & $0.001(-0.16)$ \\
\hline Constant & $3.247 * * *(31.18)$ & -- & -- \\
\hline$\lambda / \rho$ & -- & $0.868 * * *(-36.3)$ & $0.762 * * *(-21.03)$ \\
\hline $\mathrm{N}$ & 252 & 252 & 252 \\
\hline $\mathrm{R}^{2}$ & 0.46 & 0.109 & 0.481 \\
\hline Log likelihood & -- & 255.405 & 257.373 \\
\hline
\end{tabular}

Note: Figures in parentheses are t-statistics, ${ }^{* * *}, * *$ and $*$ denote a significance of $1 \%, 5 \%$ and $10 \%$, respectively.

significantly. In the SEM, model 2 shows that increasing per capita energy consumption, population, car density and higher portion of the secondary industry (e.g., manufacturing and food industries) relative to the service industry would lead to increasing haze pollution. However, higher per capita GDP are corresponded by less haze pollution. In the SLM, model 3 shows that per capita energy consumption, the portion of the secondary industry relative to the service industry, FDI and population are all positively correlated with haze pollution. The results of model 2 and model 3 are basically consistent, but there is a large difference between them and model 1, especially about the effect of the portion of the secondary industry relative to the service industry. From the condition of SLM and SEM, both $\lambda$ and $\rho$ are greater than 0 and they are all significant at the 0.01 level. This denotes that the regional haze pollution has obvious spatial "spillover effect". Spatial factors play an important role in the regional haze pollution and they cannot be ignored. Due to the natural geographical reasons, such as wind direction and closeness in location, the haze pollution in one area will be affected by neighboring areas. In addition, socio-economic factors such as economic connection and population flows between cities will further deepen the spatial correlation of haze pollution among areas. It can be seen that trans-regional pollutant transport and industrial transfer are important reasons for the formation of haze pollution, and it is difficult to fundamentally solve regional haze pollution problems.

\section{Spillover Effect Analysis of Factors}

Based on the spatial correlation LM test, SLM is chosen, and the Hausman test shows that the fixed effect of SLM is better than SLM with random effect. LeSage and Pace (2014) [38] points out that the coefficients directly obtained from spatial econometric models are biased when using the point estimation method to test whether the spatial variables have spillover effects. The coefficients of the explanatory variables do not represent the true partial regression coefficients, and they propose that the coefficient estimation of explanatory variables need to be decomposed into direct effects and indirect effects by using the method of partial differentiation. According to the method and the SLM results, we obtain the direct and indirect effects of explanatory variables and control variables on the haze pollution, as shown in Table 5. Some useful conclusions are obtained as follows.

Firstly, the coefficient of the direct effect of per capita energy consumption is 0.100 at $1 \%$ significance

Table 5. Direct and indirect effects of various variables on haze pollution in SLM.

\begin{tabular}{|c|c|c|c|}
\hline Variables & Direct & Indirect & Total \\
\hline $\ln \mathrm{ECP}$ & $0.100 * * *$ & $0.219^{* * *}$ & $0.319 * * *$ \\
\hline $\ln \mathrm{GDPP}$ & 0.002 & -0.002 & 0.000 \\
\hline $\ln \mathrm{GDPP} 2$ & -0.013 & -0.028 & -0.041 \\
\hline $\ln \mathrm{INDUS}$ & $0.071 * * *$ & $0.156^{* *}$ & $0.227 * *$ \\
\hline $\ln \mathrm{FDI}$ & $0.020 * *$ & $0.045^{* *}$ & $0.065^{* *}$ \\
\hline $\ln \mathrm{POPU}$ & $0.121 * * *$ & $0.266^{* * *}$ & $0.387 * * *$ \\
\hline $\ln \mathrm{CARDEN}$ & 0.001 & 0.004 & 0.006 \\
\hline
\end{tabular}

Note: ***,**and $*$ denote a significance of $1 \%, 5 \%$ and $10 \%$, respectively. 
level, which indicates that per capita energy consumption promotes haze pollution significantly. Our result is consistent with others' conclusion about the relationship between environmental pollutants and energy consumption [39, 40]. Moreover, it is notable that its indirect effect is also positive in this study, which shows that the increase of per capita energy consumption in the city has a spillover effect. In other words, an increase in per capita energy consumption of each city will not only promote local haze pollution, but also promote haze pollution in other neighboring cities. This is an important cause of air haze pollution in the overall area.

Secondly, both direct and indirect effects of FDI and the portion of the secondary industry relative to the service industry in increasing haze pollution are significant. Guangdong is still in the process of rapid urbanization and industrialization. Industrial development consumes large amounts of fossil fuel and electricity. Non-fossil energy consumption in Guangdong has seen a continuous increase in recent years, but it only accounts for $25.6 \%$ of the total energy consumption in 2017. Most of the electricity in Guangdong is still generated from fossil fuels, especially coal and oil, which may emit large quantities of air pollutants. The direct, indirect and total effects of FDI are $0.02,0.045$ and 0.065 respectively at 5\% significance level. This denotes that FDI has a positive effect on haze pollution in Guangdong, which provides support for pollution haven hypothesis (PHH), which posits that production within polluting industries will shift to locations with lax environmental regulation [41]. The impact of foreign direct investment on the environment is related to the FDI structure [42]. Because of strict environmental standards in developed countries, many multinational corporations build pollution-intensive factories in developing countries, where the environmental regulations are laxer. This could effectively reduce the environmental cost while producing cheaper, more competitive products in the international market. In 2017, the amount of foreign capital utilized by Guangdong reached about \$23 billion, accounting for $17.48 \%$ of the total foreign capital being spent in China. In addition, the competition for attracting FDI in Guangdong is very intense between local city governments under the incentive mechanism, with GDP as an important achievement. Hence, adjacent cities without competitive advantage attracted more foreign investments with high pollution industries to increase GDP.

Finally, the direct, indirect and total effects of population number are 0.121, 0.266 and 0.387 respectively at $1 \%$ significance level. This concludes that population agglomeration deteriorates air quality directly and significantly. The more people there are, the more energy is consumed. And the spillover effect of population also exists. The possible explanation for this phenomenon is that there is intense competition between neighboring cities for attracting labor population inflows. The city directly adopts subsidies such as housing and wages to compete for human resources. More people come to the city, causing more energy consumption and then more haze pollution. Hence, addressing smog pollution in densely populated cities such as Guangzhou, Dongguan and Foshan is critical and urgent for public health. In this study, the effects of per capita GDP and EKC hypothesis are not supported. The impact of car density on haze pollution is positive but not significant in Guangdong.

\section{Conclusions}

Using the exploratory spatial data analysis method and spatial econometric models, this study analyzes the effect of energy consumption, industrial structure, FDI, car density, economic growth and population on haze pollution in Guangdong during 2005-2016. The main conclusions are as follows:

(1) There is a significant positive spatial autocorrelation of haze pollution in 21 cities from 2005 to 2016, which indicates that the haze pollution in Guangdong does not follow a random distribution. There may be an agglomeration in the highly polluted areas and low pollution areas also gather together. Spatial cluster effects of haze pollution in Guangdong are obvious and stable, which "high-high" aggregation areas are located in the Pearl River Delta region centered on Guangzhou, Foshan, Zhongshan and Dongguan.

(2) This study uses spatial econometric models to further verify the spatial dependence of haze pollution in Guangdong. Our results show that the direct and indirect effects of energy consumption are positive and significant at the $1 \%$ level.

(3) We find FDI and the ratio of the secondary industry relative to the service industry also do play important roles in haze pollution, and both of them have positive direct and indirect effects on air pollution. And the PPH is supported in Guangdong. At the same time, economic growth and car density are not significant factors.

Our results can help the Guangdong government understand the spatial autocorrelation of haze pollution in its 21 cities and its relationship with those influencing factors. Therefore, our findings may have important policy implications. Firstly, it is urgent for the governments of Guangzhou, Dongguan, Zhongshan and Foshan to take a positive attitude towards the work of haze pollution reduction. Those four cities should be set up as the priority haze-pollution-reduction areas.

Secondly, joint efforts of cities to prevent and control haze pollution is very important and necessary, because of the existence of spatial spillover effects of haze pollution in Guangdong. It is vital to clarify the main functions and positioning of different cities in Guangdong-Hong Kong-Marco Greater Bay Area, avoid the vicious competition of industry development and 
population inflow, and strengthen the coordination and planning linkage between urban areas.

Thirdly, actively introducing green and environmentally friendly foreign direct investment, accelerating industrial transformation and technological upgrading, strengthening environmental regulation, optimizing energy structure, and enhancing residents' environmental awareness and actions are essential for smog pollution control in Guangdong.

\section{Acknowledgements}

This research was funded by the Development and Reform Commission of Shenzhen ("Shenzhen Low Carbon City Big Data Engineering Laboratory", grant No. [2017]1089), the Provincial Party Committee Propaganda Department of Guangdong ("Research on the Construction of 'Beautiful Guangdong' and Low Carbon Demonstration Province", grant No. LLYJ1310) and the Development and Reform Commission of Shenzhen ("Coping with Climate Change and the construction of low carbon economy discipline", grant No. [2018]725).

\section{Conflict of Interest}

The authors declare no conflict of interest.

\section{References}

1. ELSER M., HUANG RU J., WOLF R., SLOWIK J. G., WANG Q., CANONACO F., LI G., BOZZETTI C., DAELLENBACH K.R., HUANG Y., ZHANG R., LI Z., CAO J., BALTENSPERGER U., EL-HADDAD I., ANDRÉ P. New insights into $\mathrm{PM}_{25}$ chemical composition and sources in two major cities in China during extreme haze events using aerosol mass spectrometry. Atmospheric Chemistry and Physics, 16 (5), 3207, 2016.

2. NEIRA M., PRÜSS-USTÜN A. Preventing disease through healthy environments: A global assessment of the environmental burden of disease. Toxicology Letters, 259 (2016), S1, 2016.

3. COHEN A.J., BRAUER M., BURNETT R., ANDERSON H.R., FROSTAD J., ESTEP K., BALAKRISHNAN K., BRUNEKREEF B., DANDONA L., DANDONA R., FEIGIN,V., FREEDMAN G., HUBBELL B., JOBLING A., KAN H., KNIBBS L., LIU Y., MARTIN R., MORAWSKA L., POPE C.A., SHIN H., STRAIF K., SHADDICK G., THOMAS M., VAN DINGENEN R., VAN DONKELAAR A., VOS T., MURRAY C.J.L., FOROUZANFAR M.H. Estimates and 25-year trends of the global burden of disease attributable to ambient air pollution: an analysis of data from the Global Burden of Diseases Study 2015. The Lancet, 389 (10082), 1907, 2017.

4. FU J., YUAN Z. Evaluation of Effect and Analysis of Expansion Mechanism of Synergic Emission Abatement in China's Power Industry. China Industrial Economics, (2), 43, 2017 [In Chinese].
5. MAYKUT N.N., LEWTAS J., KIM E., LARSON T.V. Source Apportionment of $\mathrm{PM}_{25}$ at an Urban IMPROVE Site in Seattle, Washington. Environmental Science and Technology, 37 (22), 5135, 2003.

6. SUN Y., ZHUANG G., TANG A., WANG Y., AN Z. Chemical characteristics of $\mathrm{PM}_{2.5}$ and $\mathrm{PM}_{10}$ in hazefog episodes in Beijing. Environmental Science and Technology, 40 (10), 3148, 2006.

7. HAN S.Q., WU J.H., ZHANG Y.F., CAI Z.Y., FENG Y.C., YAO Q., LI X.J., LIU Y.W., ZHANG M. Characteristics and formation mechanism of a winter haze-fog episode in Tianjin, China. Atmospheric Environment, 98, 323, 2014.

8. GUAN D., SU X., ZHANG Q., PETERS G.P., LIU Z., LEI Y., HE K. The socioeconomic drivers of China's primary $\mathrm{PM}_{2.5}$ emissions. Environmental Research Letters, 9 (2), 2014.

9. WEI W., MA X. Optimal Policy for Energy Structure Adjustment and Haze Governance in China. China Population, Resources and Environment, 25 (7), 6, 2015 [In Chinese].

10. LI D., WANG X. Empirical study on the effect of economic growth on haze pollution: analysis of threshold effect based on provincial panel data in China. Ecological Economy, 33 (10), 168, 2017 [In Chinese].

11. GUO A., HU A. Research on Influencing Factors of Urban Haze in China. Statistics \& Decision, 34 (19), 105, 2018 [In Chinese].

12. ZHU L., LI T., LI Y., LIU Z. The Influence of Industrial Structure Adjustment on Haze Pollution: An Empirical Study of Jing-Jin-Ji Region. Ecological Economy, 10, 141, 2018 [In Chinese].

13. CHEN S., WANG J. Evaluation and policy innovation of urban haze governance in China:taking the Yangtze River Delta Area as an example. China Population, Resources and Environment, 28 (10), 105, 2018 [In Chinese].

14. WU J., ZHANG P., YI H., QIN Z. What causes haze pollution? An empirical study of $\mathrm{PM}_{25}$ concentrations in Chinese cities. Sustainability (Switzerland), 8 (2), 1, 2016.

15. WANG L., CHEN J. Socio-economic influential factors of haze pollution in china: Empirical study by eba model using spatial panel data. Acta Scientiae Circumstantiae, 36 (10), 3833, 2016 [In Chinese].

16. SHAO S., LI X., CAO J., YANG L. China's Economic Policy Choices for Governing Smog Pollution Based on Spatial Spillover Effects. Economic Research Journal, 9, 7, 2016 [In Chinese].

17. LIU X., JIANG K. Empirical Study on the Spatial Effect of China's Haze Pollution --Influence Factors Based on PM2.5. Science \& Technology Management Research, (12), 247, 2017 [In Chinese]

18. TANG D., LI L., YANG Y. Spatial econometric model analysis of foreign direct investment and haze pollution in China. Polish Journal of Environmental Studies, 25 (1), 317, 2016.

19. DONG F., ZHANG S., LONG R., ZHANG X., SUN Z. Determinants of haze pollution: An analysis from the perspective of spatiotemporal heterogeneity. Journal of Cleaner Production, 222, 768, 2019.

20. LIU Y., DONG F. How industrial transfer processes impact on haze pollution in China: An analysis from the perspective of spatial effects. International Journal of Environmental Research and Public Health, 16 (3), 423, 2019.

21. TANG D., XU H., YANG Y. Mutual influence of energy consumption and foreign direct investment on haze 
pollution in china: A spatial econometric approach. Polish Journal of Environmental Studies, 27 (4), 1743, 2018.

22. DONG F., YU B., PAN Y. Examining the synergistic effect of $\mathrm{CO}_{2}$ emissions on $\mathrm{PM}_{2.5}$ emissions reduction: Evidence from China. Journal of Cleaner Production, 223, 759, 2019.

23. LIU X., LI L., GE J., TANG D., ZHAO S. Spatial spillover effects of environmental regulations on china's haze pollution based on static and dynamic spatial panel data models. Polish Journal of Environmental Studies, 28 (4), 2231, 2019.

24. LIU K., LIN B. Research on influencing factors of environmental pollution in China: A spatial econometric analysis. Journal of Cleaner Production, 206, 356, 2019.

25. Guangdong Statistical Yearbook. Available online: http:// stats.gd.gov.cn/gdtjnj/index.html (accessed on 18.9.2019).

26. VAN DONKELAAR A., MARTIN R.V, BRAUER M., HSU N.C., KAHN R.A., LEVY R.C., LYAPUSTIN A., SAYER A.M., WINKER D.M. Global Annual $\mathrm{PM}_{2.5}$ Grids from MODIS, MISR and SeaWiFS Aerosol Optical Depth (AOD) with GWR, 1998-2016. Palisades, NY: NASA Socioeconomic Data and Applications Center (SEDAC), 2018.

27. ANSELIN L. Local Indicators of Spatial Association LISA. Geographical Analysis, 27 (2), 93, 1995.

28. MORAN P.A.P. A Test for the Serial Independence of Residuals. Biometrika, 37 (1/2), 178, 1950.

29. EHRLICH P.R., HOLDREN J.P. Impact of Population Growth. Science, 171 (3977), 1212, 1971.

30. DIETZ T., ROSA E.A. Rethinking the Environmental Impacts of Population, Affluence and Technology. Human Ecology Review, 1 (2), 277, 1994.

31. WEN L., CAO Y., WENG J. Factor decomposition analysis of China's energy-related $\mathrm{CO}_{2}$ emissions using extended STIRPAT model. Polish Journal of Environmental Studies, 24 (5), 2261, 2015.

32. KUZNETS S. Economic Growth and Income Inequality. The American Economic Review, 45 (1), 1, 1955.
33. GROSSMAN G.M., KRUEGER A.B. Economic growth and the environment. The quarterly journal of economics, 110 (2), 353, 1995.

34. HU J., HERNANDEZ-DEL-VALLE A., MARTINEZGARCIA M.A. Environmental Pollution and Economic Growth in China: A Test of the Environmental Kuznets Curve. Journal of Geoscience and Environment Protection, 05 (10), 92, 2017.

35. KANG Y.Q., ZHAO T., YANG Y.Y. Environmental Kuznets curve for $\mathrm{CO} 2$ emissions in China: A spatial panel data approach. Ecological Indicators, 63, 231, 2016.

36. WANG S., YANG F., WANG X., SONG J. A microeconomics explanation of the environmental Kuznets curve (EKC) and an empirical investigation. Polish Journal of Environmental Studies, 26( 4), 1757, 2017.

37. ANSELIN L., BERA A.K., FLORAX R., YOON M.J. Simple diagnostic tests for spatial dependence. Regional Science and Urban Economics, 26 (1), 77, 1996.

38. LESAGE J.P., PACE R.K. Interpreting spatial econometric models. Handbook of Regional Science; Fischer M., Nijkamp P. Eds.; Springer, Berlin, Heidelberg, 1535, 2014.

39. YANG X., WANG S., ZHANG W., LI J., ZOU Y. Impacts of energy consumption, energy structure, and treatment technology on $\mathrm{SO}_{2}$ emissions: A multi-scale LMDI decomposition analysis in China. Applied Energy, 184, 714, 2016.

40. ZHANG Y.L., CAO F. Is it time to tackle $\mathrm{PM}_{2.5}$ air pollutions in China from biomass-burning emissions? Environmental Pollution, 202, 217, 2015.

41. MILLIMET D.L., ROY J. Empirical Tests of the Pollution Haven Hypothesis When Environmental Regulation is Endogenous. Journal of Applied Econometrics, 31 (4), 652, 2016.

42. DOYTCH N., UCTUM M. Globalization and the environmental impact of sectoral FDI. Economic Systems, 40 (4), 582, 2016. 
